\title{
Factors Affecting Energy Efficiency and CO2 Reduction in The Manufacturing Firms of Thailand
}

\author{
Worawit Janchai ${ }^{1, *}$, Anurak Panyanuwat ${ }^{2}$ \\ ${ }^{1,2}$ Chiang Mai University, Thailand. \\ ${ }^{1}$ worawit.jc@gmail.com*; 2 Dr_anurak@hotmail.com; \\ * corresponding author
}

\begin{abstract}
The current study investigated the effects of management commitment, energy awareness, energy knowledge, energy audit towards energy efficiency which was further examined towards $\mathrm{CO} 2$ reduction in manufacturing firms of Thailand. The sample of this study was gathered from manufacturing firms of Thailand and the sample size was 148 responses. The data was collected in a quantifiable manner and was analyzed using PLS-SEM. The paper should that energy audits have a positive and significant effect on energy efficiency. Energy awareness has a positive and significant effect on energy efficiency. Energy efficiency has a positive and significant effect on CO2 reduction. Energy knowledge has a positive and significant effect on energy efficiency. The management committee has a positive and significant effect on energy efficiency. Investing in human resource growth provides signs of determination to produce the desired results and, combined with administration encouragement and determination, the expected success can be achieved.
\end{abstract}

Keywords: Management Commitment; Energy Awareness; Energy Knowledge; Energy Audit; Energy Efficiency; CO2 Reduction; Thailand.

\section{Introduction}

The amount of atmospheric CO2 has increased since monitoring started in 1958. The report indicates that fossil fuel combustion contributes around $67 \%$ of the overall $\mathrm{CO} 2$ output worldwide to the environment today [9]. $\mathrm{CO} 2$ is partially consumed by the oceans of the world, but because of the increase in pollutants, the resulting contamination of the same waters is gradually contributing to environmental and biologic shifts, as the increase of pollution in the atmosphere of the environment contributes to global warming and climate shifts [21]. Although carbon dioxide is not a sole gas of the green-house adding to the issue, it also is one of the most readily human-produced gas of the greenhouse [57].

In addition, "CO2 is classified as a greenhouse gas and is created as a by-product of consuming nonrenewable fossil fuels such as coal, petroleum, and natural gas as energy sources" [35]. The environmental damage caused by the discharge of $\mathrm{CO} 2$ leads to climate change, which further exacerbates the economic risks of extreme weather events such as floods, which in turn can lead to supply chain instability and operational losses [70]. The prospect of financial disruption plus the upsetting of world-wide production chains as a consequence of global warming and climate change had generated a growing incentive among both regulators and the public to understand the risk of uncontrolled $\mathrm{CO} 2$ emissions [10]. The evaluation of economic and environmental costs was the reason behind it Moretti et al [46], it had concluded regional climate change issues. One illustration of this is the Kyoto Protocol and the Intergovernmental Panel on Climate Change (IPCC), which pledged signatories to minimize greenhouse gas discharge.

Moreover, since research shows that increased energy use is the major reason of ever growing carbon dioxide emissions, improving energy efficiency is significant in achieving "sustainable economic growth" while reducing ecological and societal effects [56]. On the one side, power has become the main factor of economic development and rising energy use has historically been observed as the main reason or growth in the economy [49]. Towards the other side, research indicates causal relations between energy use and the deterioration of environmental and social wellbeing. Some countries have been careful about introducing drastic reforms that disturb the equilibrium between economic prosperity and the well-being of their people and the environment [58]. 
Analysis works have represented that the corporate implementation of energy efficiency had been lagging and certain organizations have demonstrated poor operational and administrative dedication to fostering innovation and energy-efficient expenditure. This has mainly been attributed to factors including insufficient technological expertise [2], lacking information about the possible advantages of energy conservation, decision-makers lack the courage to interrupt predefined procedures that cause organizational failures, and the ignorance of the employees as well [4]. While the effects of energy conservation were well established, this research was carried out mainly in the sense of developing nations like the Netherlands, Sweden, and Germany [65]. CO2 pollution in Asian countries was growing traction in urban growth as ecological destruction and human health problems had become more visible to common man [45]. Thailand had seen little progress in achieving energy quality amid a multitude of programs and policies aiming at energy efficiency; problems and opportunities exist and must be thoroughly grasped [47][64]. A variety of reports had shown the inadequacy of the implementation of energy management in the manufacturing sector due to a shortage of workers with sufficient awareness and energy quality training [40], a lack of knowledge about energy use trends (Shrouf and Miragliotta, 2015), instability structurally and the possibility of affecting product quality. Pandurangan, Ochoa-Montaño, Ascher, and Blundell [50], energy conservation was not a concern because of a lack of dedication to management [8], yet uncertain overspending because of insufficient financial means yet deferred payments [51].

Thailand is a highly developed nation with a steadily increasing manufacturing industry from the late 1980s. All energy demand and carbon dioxide ( $\mathrm{CO} 2$ ) emissions have increased in line with the growing economization as a consequence of industrialization [60]. The manufacturing sector was the one that emitted the most $\mathrm{CO} 2$ in the last two decades, particularly after the mid-2000s. The increasing energy use in the sector has raised $\mathrm{CO} 2$ emissions. Over time, energy use rose by $5 \%$ per year, contributing to a $6 \%$ rise in $\mathrm{CO} 2$ emissions [16]. Hence, it had been assumed vital to make attempts to minimize $\mathrm{CO} 2$ pollution in Thailand's factories to tackle the climate change issue. $\mathrm{CO} 2$ emissions may be lowered either explicitly by declining the $\mathrm{CO} 2$ emissions from specific factories or by growing the pollution rate of each industry $(\mathrm{CO} 2$ emissions per unit of production) [16]. Hence, the current study investigated the effects of management commitment, energy awareness, energy knowledge, energy audit towards energy efficiency which was further examined towards $\mathrm{CO} 2$ reduction in manufacturing firms of Thailand.

Although the demand was that to account for $\mathrm{CO} 2$ pollution in the manufacturing sector, businesses still consider it challenging to introduce successful carbon mitigation schemes, partially because of the difficulty of identifying the origins and triggers of excessive carbon emissions X. Zhang, Luo, and Skitmore [67] also partially because of a shortage of obvious financial related benefits [69] it is particularly valid for smaller, with low power utilization [7] if convincing data will prove the company's environmental gains from such reduction [26]. Although energy management principles reflect good practice, the best energy efficiency strategies still lack suitable models [34]. The lack of best practice models and observational energy efficiency research concerning manufacturing companies is especially serious in developing countries.

The rest of the paper had been structured as follows: the literature review and formulation of hypotheses had been included in Section 2; Section 3 presents the research methodology and data collection methods, whereas the analyses and hypothesis testing had been presented in Section 4; finally, Section 5 draws the conclusions derived from this research as well as identifies its recommendations.

\section{Literature Review}

A suggested theoretical structure was conceptualized based on the conceptual model. The institutional theory had been used to describe the connection between the structures to help the theoretical framework. The three drivers of "institutional theory" that allow companies to act. First one is manipulative driver, this involves legal pressures from authority structures including regulatory legislation. Enforcement of regulations and guidance from regulatory bodies enables businesses to increase their understanding of critical energy conservation for a prosperous future [61]. The normative driver is the second factor that drives companies to meet with laws that are deemed a legal entity. Upper management needs to encourage awareness of resources and effective usage of all shareholders [55]. This was not just about compliance with environmental standards but also regarding cutting energy costs. In this model, the final driver of the institutional theory was imitated. Manufacturing companies can put a heavy focus on energy efficiency strategies as they hear and look their 
rivals' stories of achievement in corporate targets. It was when an organization tried to imitate effective competitors [24]. However, by the intervention of internal or external bodies (government agencies) which could supervise and audit it, the efficient and effective use of energy in the manufacturing sector can be observed.

The production of energy-efficient technology for energy-intensive industries had gained vital increment Sauvé, Bernard, and Sloan [54]. Practices in energy conservation were posited as effective ways of rising energy use. However, an empirical analysis of the application of energy management and its effects was required to help the potential development of energy quality in industry [12]. Rigid obedience to shortened financial policies and models excluding researching administrational practices and avoidance towards change had not helped to advance empirical understanding, particularly because evidence indicates a wide variance in success in diverse cultures incorporate [62]. To resolve the existing hindrances various mechanisms had been designed in this regard, however, because of the working environment and regional economic differences, under the standardized indigenous setting such practices were needed to be researched and verified again. Abdmouleh, Alammari, and Gastli [1] argued that management commitment should be inspected under the development of initial energy performance. With the help of technological, environmental, social, and economic dimensions, engineers must be trained to promote an energy-efficient environment and they can further assist the organization to implement it [6].

Moreover, management commitment, communication of energy improvement, and training play a significant role in the implementation of the practice of energy conservation and spreading awareness as well [3]. Gupta, Jain, and Vaszkun [29] observed that communicating progress was essential to the diffusion of information such that those within the same network might find a similar approach for their region. They postulated that peers were considered to be more trustworthy and that oral knowledge was regarded to be more reliable than written data. Canton [13] indicated that appropriate training of skills and energy awareness programs coupled with good higher administration assistance will counter opposition to reform and allow creating self-belief rather than distrust or anger against power administration practices. Through related work, Naidoo [48] suggested that information and understanding should integrate "energy-efficient life cycle decision-making" into the corporate culture of a company where energy-saving activities were scheduled, the importance of energy conservation was unquestioned, and the achievement of efficiency of energy was second nature.

Furthermore, piecemeal solutions to eliminating emissions and energy had been performed a little in the past. Yet such strategies were not able to make substantial advancement towards zero-emission production by using a systemic method [11]. Because of a lack of awareness of the importance of energy efficiency, Kluczek and Olszewski [36] proposed creating a simpler paradigm that demonstrates pollution mitigation by organizational changes driven by cooperation between businesses in the same supply chain to work together to minimize costs and emissions. Fernando, Bee, Jabbour, and Thomé [22] highly suggested energy auditing as the first cost-effective measure an organization had to take to create knowledge of future successful energy investments. This was because environmental assessments for energy efficiency upgrades had been observed to contribute to better adoption levels.

However, this result was not without its critics, as Quartey, Turkson, Abor, and Iddrisu [52] concluded that energy audits will not necessarily contribute to increased percentage of acquiring when certain fundamental considerations such as financial stability and knowledge asymmetry were tackled first. They claim that policymakers need to consider the resources they use, and the sophistication of decision-support systems needs to be relevant to their skills. The study also stated that although understanding was a fundamental requirement, business managers remain disinterested in ecological problems, particularly in "small and middle-sized enterprises" (SMEs). That was because substantial variations had been identified between the activities of SMEs and the experiences of various economic sectors [44].

Improving the four areas of energy management activities (management participation, environmental understanding, environmental expertise, and energy audits) may boost manufacturing firms' capacity to deliver better goods and services with effective energy savings. Cooremans and Schönenberger [19]; F. Zhang, $\mathrm{Hu}$, Langari, and Cao [66] will address energy management and energy performance in greater depth. They also suggested a connection between energy management enhancements and improved efficiency; therefore, energy management strategies are constructively linked to energy efficiency. On the basis of the above mentioned information, we can hypothesize that: 
H1: Management commitment is positively related to energy efficiency.

H2: Energy awareness is positively related to energy efficiency.

H3: Energy knowledge is positively related to energy efficiency.

H4: An energy audit is positively related to energy efficiency.

Fernando and Hor [23]; Manan, Nawi, Alwi, and Klemeš [43]; Tozlu, Özahi, and Abuşoğlu [59] claimed that advances in energy management can minimize carbon pollution by minimizing primary usage of electricity or by using waste resources in other procedures. Those involve heating or cooling and maximizing idle speeds of machinery during start-up, service, and idle periods. There was a claim that reducing carbon emission was a product of changes in energy production, hence, it is hypothesized that:

H5: Energy efficiency is positively related to carbon emissions reduction.

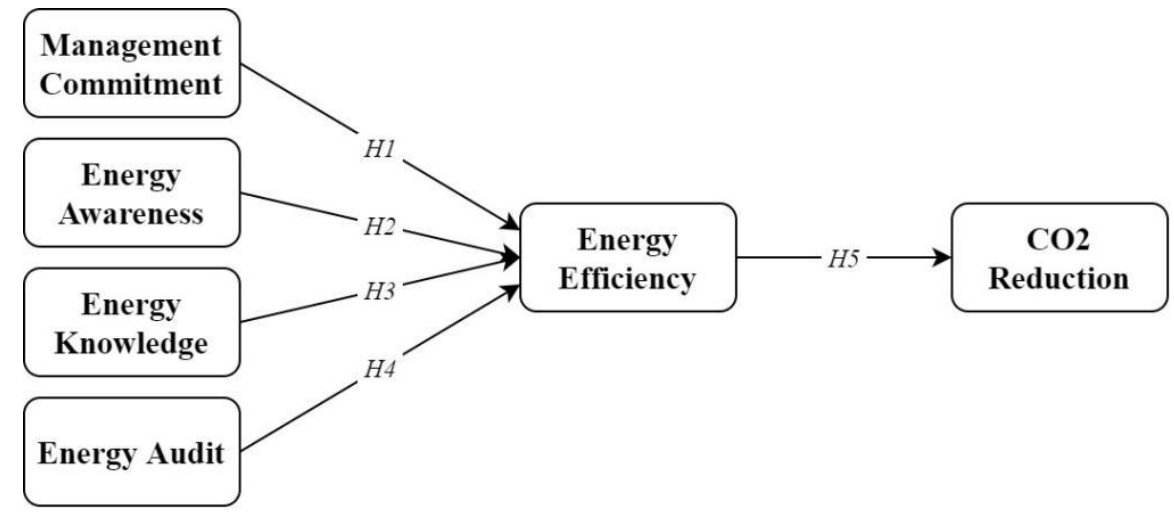

Fig. 1. Research Framework

\section{Methodology}

\subsection{Research Design}

The explanatory type of investigation was used in the study for the confirmation of an existing theory. The explanatory type of investigation deals with the explanation of occurring of a phenomenon with the help of hypothesis testing [5]. In the same context, the correlational research design was used in the paper to evaluate the correlation between the variables of the study. The correlational research design is where the relationship between the construct is examined [38]. Similarly, the survey strategy was used in the study as it allows a wide variety of data to be collected to reach more generalizable conclusions. The survey strategy deals with collection from the target population by asking the respondents the structured questions in person, on-call, or on the internet [32].

\subsection{Sampling Design}

The target population of the study is the employees of the manufacturing firms of Thailand. The manufacturing sector of Thailand contributed to about $27.4 \%$ of Thailand's GDP and includes about $16 \%$ of all the labor force of Thailand [14]. The sample size of the study was estimated with the help of $50+8 \mathrm{~K}$ formula; hence, the recommended [39], the study has therefore collected 148 responses from the sample population. The purposive non-probability sampling technique was used in the study as the data had to be collected from individuals that can provide data with rich information. The purposive sampling is a sampling technique where the data is collected from the experts and professionals in the industry for the data to be rich in information [17]. The following table 1 discussion describes the background of the respondents.

Table. 1. Demographics Statistics $(\mathrm{N}=148)$

\begin{tabular}{lccc}
\hline & & Frequency & Percent \\
\hline Firm Size (Employees) & Less than 250 & 17 & 11.5
\end{tabular}




\begin{tabular}{llcc} 
& $251-500$ & 37 & 25 \\
$501-1000$ & 57 & 38.5 \\
More than 1000 & 37 & 25 \\
Less than 3 years & 19 & 12.8 \\
Experience (years) & 3ears to 6 years & 35 & 23.6 \\
& 7 years to 10 years & 55 & 37.2 \\
More than 10 years & 39 & 26.4 \\
Production & 18 & 12.2 \\
Department & Warehouse Management & 35 & 23.6 \\
& Procurement & 56 & 37.8 \\
& Distribution & 39 & 26.4 \\
\hline
\end{tabular}

\subsection{Data Collection}

A self-structured question was used in the study to collect the data from the sample population. The questionnaire was distributed among the respondents in person as well as online [28]. The five-point Likert scale was used in the self-structured questionnaire as it creates lesser confusion among the respondents as well as it increases the response rate [20].

\subsection{Data Analysis}

The PLS-SEM was used as the data analysis technique in the study. The PLS-SEM is a data analysis technique used for the testing of present theory and evaluates the relationship between the variables [15] as it can help in the expansion of the theory on which the model of the study is based on [37].

\subsection{Ethical Considerations}

The ethical considerations were focused on by the researcher as the voluntary participation of the respondents was ensured beforehand. Also, the participants were ensured about the confidentiality of their data and information. Further, no person was harmed in any way while the study was conducted [18].

\section{Data Analysis}

\subsection{Measurement Model}

Table 2 represents the results of the measurement model.

Table. 2. Measurement Model

\begin{tabular}{llccc}
\hline Variables & Items & Loadings & $\begin{array}{c}\text { Composite } \\
\text { Reliability }\end{array}$ & $\begin{array}{c}\text { Average Variance } \\
\text { Extracted (AVE) }\end{array}$ \\
\hline CO2 Reduction & CO2R1 & 0.887 & 0.844 & 0.731 \\
& CO2R2 & 0.821 & & \\
Energy Audit & EA1 & 0.930 & & 0.820 \\
& EA3 & 0.861 & 0.932 & \\
Energy Awareness & EA4 & 0.924 & & 0.722
\end{tabular}




\begin{tabular}{lllll} 
& EAN3 & 0.918 & & \\
& EAN4 & 0.833 & & \\
Energy Efficiency & EE2 & 0.927 & & 0.802 \\
& EE3 & 0.863 & & \\
Energy Knowledge & EK1 & 0.950 & \multirow{2}{*}{0.955} & 0.913 \\
& EK2 & 0.961 & & \\
Management Commitment & MC1 & 0.925 & \multirow{2}{*}{0.934} & 0.876
\end{tabular}

The values of outer loadings are recommended to be greater than 0.70 for perfect retention. As for composite reliability, the recommended [31] values should be greater than 0.70; whereas, for AVE the recommended [53] values should be greater than 0.50 . The table showed that the values of outer loadings, CR, and AVE were greater than the recommended values; hence, the measurement model has been achieved.

\subsection{Discriminant Validity}

Table 3 represents the results of Fornell and Larcker [25] criterion for discriminant validity.

Table. 3. Fornell-Larcker Criterion

\begin{tabular}{lcccccc}
\hline & CO2R & EA & EAN & EE & EK & MC \\
\hline CO2 Reduction & $\mathbf{0 . 8 5 5}$ & & & & & \\
Energy Audit & 0.643 & $\mathbf{0 . 9 0 6}$ & & & & \\
Energy Awareness & 0.530 & 0.379 & $\mathbf{0 . 8 5 0}$ & & & \\
Energy Efficiency & 0.574 & 0.655 & 0.471 & $\mathbf{0 . 8 9 6}$ & & \\
Energy Knowledge & -0.248 & -0.246 & -0.637 & -0.196 & $\mathbf{0 . 9 5 6}$ & \\
Management Commitment & -0.060 & -0.077 & -0.347 & -0.054 & 0.567 & $\mathbf{0 . 9 3 6}$ \\
\hline
\end{tabular}

The values present in bold and diagonal settings were greater than the values present to them in vertical and horizontal settings as recommended by Fornell and Larcker [25], hence, discriminant validity has been achieved using Fornell \& Larcker criterion.

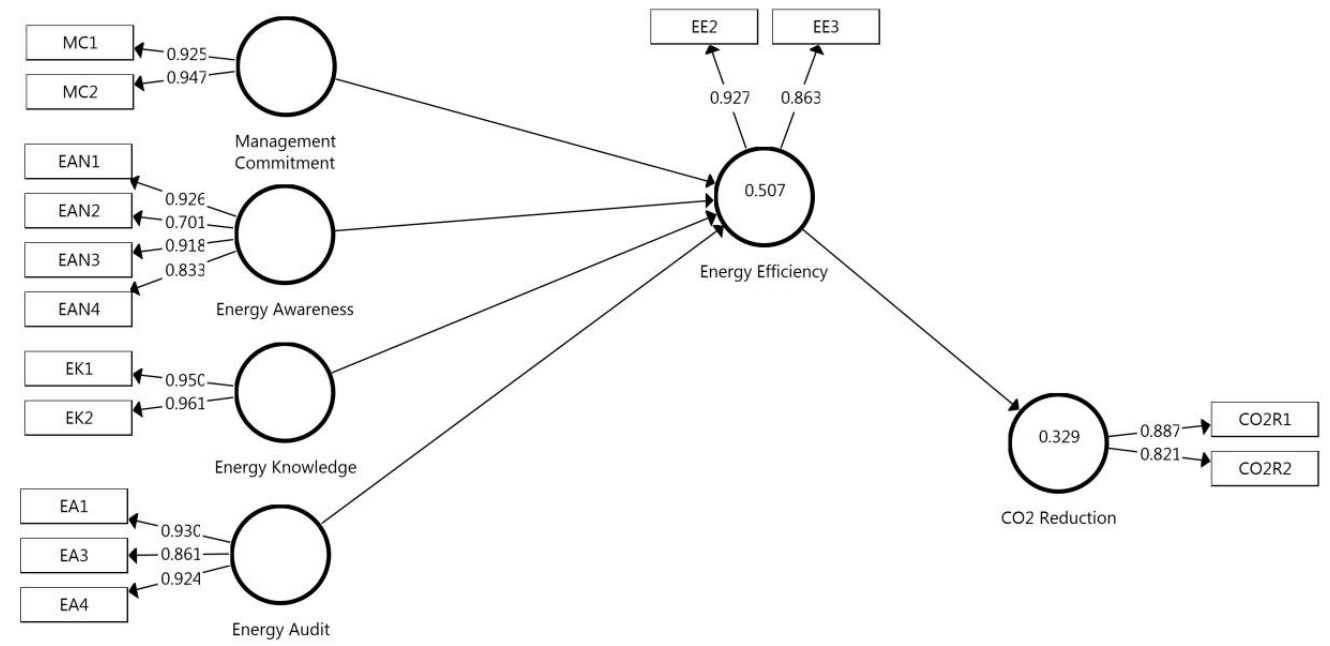

Fig. 2. PLS Algorithm using SmartPLS 
Table 4 represents the results of cross-loadings for discriminant validity

Table. 4. Crossloadings

\begin{tabular}{lcccccc}
\hline & CO2R & EA & EAN & EE & EK & MC \\
\hline CO2R1 & $\mathbf{0 . 8 8 7}$ & 0.633 & 0.658 & 0.538 & -0.546 & -0.333 \\
CO2R2 & $\mathbf{0 . 8 2 1}$ & 0.450 & 0.203 & 0.435 & 0.198 & 0.298 \\
EA1 & 0.588 & $\mathbf{0 . 9 3 0}$ & 0.414 & 0.537 & -0.334 & -0.037 \\
EA3 & 0.437 & $\mathbf{0 . 8 6 1}$ & 0.164 & 0.493 & -0.162 & -0.067 \\
EA4 & 0.682 & $\mathbf{0 . 9 2 4}$ & 0.417 & 0.709 & -0.183 & -0.097 \\
EAN1 & 0.421 & 0.294 & $\mathbf{0 . 9 2 6}$ & 0.484 & -0.661 & -0.390 \\
EAN2 & 0.251 & 0.289 & $\mathbf{0 . 7 0 1}$ & 0.317 & -0.458 & -0.596 \\
EAN3 & 0.486 & 0.408 & $\mathbf{0 . 9 1 8}$ & 0.419 & -0.619 & -0.203 \\
EAN4 & 0.644 & 0.303 & $\mathbf{0 . 8 3 3}$ & 0.357 & -0.386 & -0.019 \\
EE2 & 0.610 & 0.667 & 0.402 & $\mathbf{0 . 9 2 7}$ & -0.177 & 0.121 \\
EE3 & 0.390 & 0.484 & 0.454 & $\mathbf{0 . 8 6 3}$ & -0.175 & -0.278 \\
EK1 & -0.205 & -0.306 & -0.659 & -0.174 & $\mathbf{0 . 9 5 0}$ & 0.617 \\
EK2 & -0.266 & -0.174 & -0.565 & -0.199 & $\mathbf{0 . 9 6 1}$ & 0.476 \\
MC1 & -0.139 & -0.062 & -0.283 & -0.046 & 0.615 & $\mathbf{0 . 9 2 5}$ \\
MC2 & 0.015 & -0.080 & -0.361 & -0.055 & 0.460 & $\mathbf{0 . 9 4 7}$ \\
\hline
\end{tabular}

The cross-loading values in bold should be greater than the values present to their horizontal settings as recommended [30], as shown in the above table, hence, discriminant validity has been achieved using crossloadings.

Table 5 represents the results of the HTMT ratio for discriminant validity.

Table 5: Heterotrait-Monotrait Ratio (HTMT)

\begin{tabular}{lcccccc}
\hline & CO2R & EA & EAN & EE & EK & MC \\
\hline CO2 Reduction & & & & & & \\
Energy Audit & 0.821 & & & & & \\
Energy Awareness & 0.730 & 0.418 & & & & \\
Energy Efficiency & 0.792 & 0.763 & 0.582 & & & \\
Energy Knowledge & 0.578 & 0.283 & 0.712 & 0.236 & & \\
Management Commitment & 0.509 & 0.084 & 0.409 & 0.281 & 0.656 & \\
\hline
\end{tabular}

The values of all constructs lower than the cutoff value of 0.85 as recommended by Henseler, Hubona, and Ray [32], hence, discriminant validity has been achieved using the HTMT ratio. 


\subsection{Structural Model}

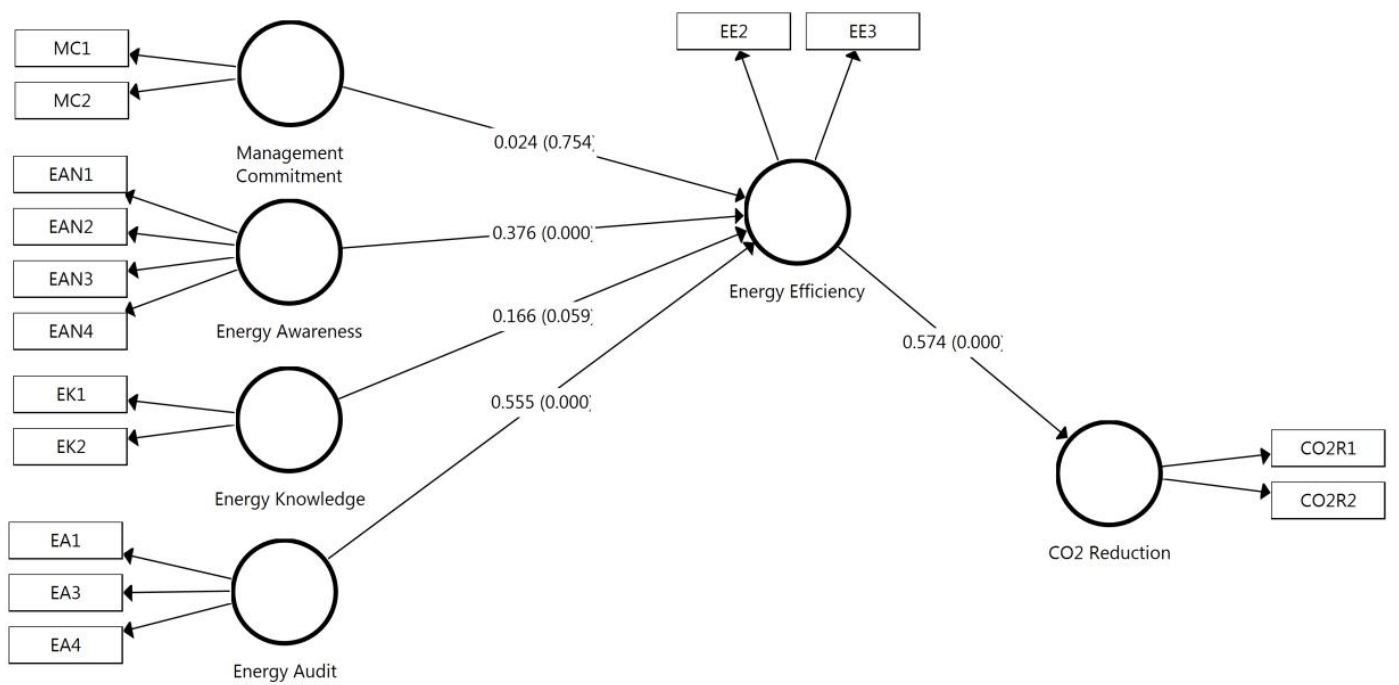

Fig. 3. PLS Bootstrapping using SmartPLS

Table 6 represents the results of hypothesis testing.

Table. 6. Hypothesis-Testing using Path Analysis

\begin{tabular}{lcccc}
\hline & Estimate & S.D. & T-Stats & Prob. \\
\hline Energy Audit -> Energy Efficiency & 0.555 & 0.044 & 12.528 & 0.000 \\
Energy Awareness -> Energy Efficiency & 0.376 & 0.066 & 5.700 & 0.000 \\
Energy Efficiency -> CO2 Reduction & 0.574 & 0.068 & 8.380 & 0.000 \\
Energy Knowledge -> Energy Efficiency & 0.166 & 0.088 & 1.892 & 0.059 \\
Management Commitment -> Energy Efficiency & 0.024 & 0.078 & 0.313 & 0.754 \\
\hline
\end{tabular}

The above table has shown that energy audit $(0.555, \mathrm{p}<0.01)$ has a positive and significant effect on energy efficiency. Energy awareness $(0.376, \mathrm{p}<0.01)$ has a positive and significant effect on energy efficiency. The energy efficiency $(0.574, \mathrm{p}<0.01)$ has a positive and significant effect on $\mathrm{CO} 2$ reduction. Energy knowledge $(0.166, \mathrm{p}<0.10)$ has a positive and significant effect on energy efficiency. The management commitment $(0.024, \mathrm{p}>0.10)$ has a positive and significant effect on energy efficiency.

Table 7 represents the results of predictive relevance.

Table. 7. Predictive Relevance

\begin{tabular}{lcc}
\hline & R Square & Q Square \\
\hline CO2 Reduction & 0.329 & 0.230 \\
Energy Efficiency & 0.507 & 0.385 \\
\hline
\end{tabular}

The above table has shown that $\mathrm{CO} 2$ reduction has been predicted by 32.9 percent and energy efficiency has been predicted by 50.7 percent. The Q-square has been found greater than absolute zero with the accuracy of 23 percent and 38.5 percent respective to each endogenous constructs. 


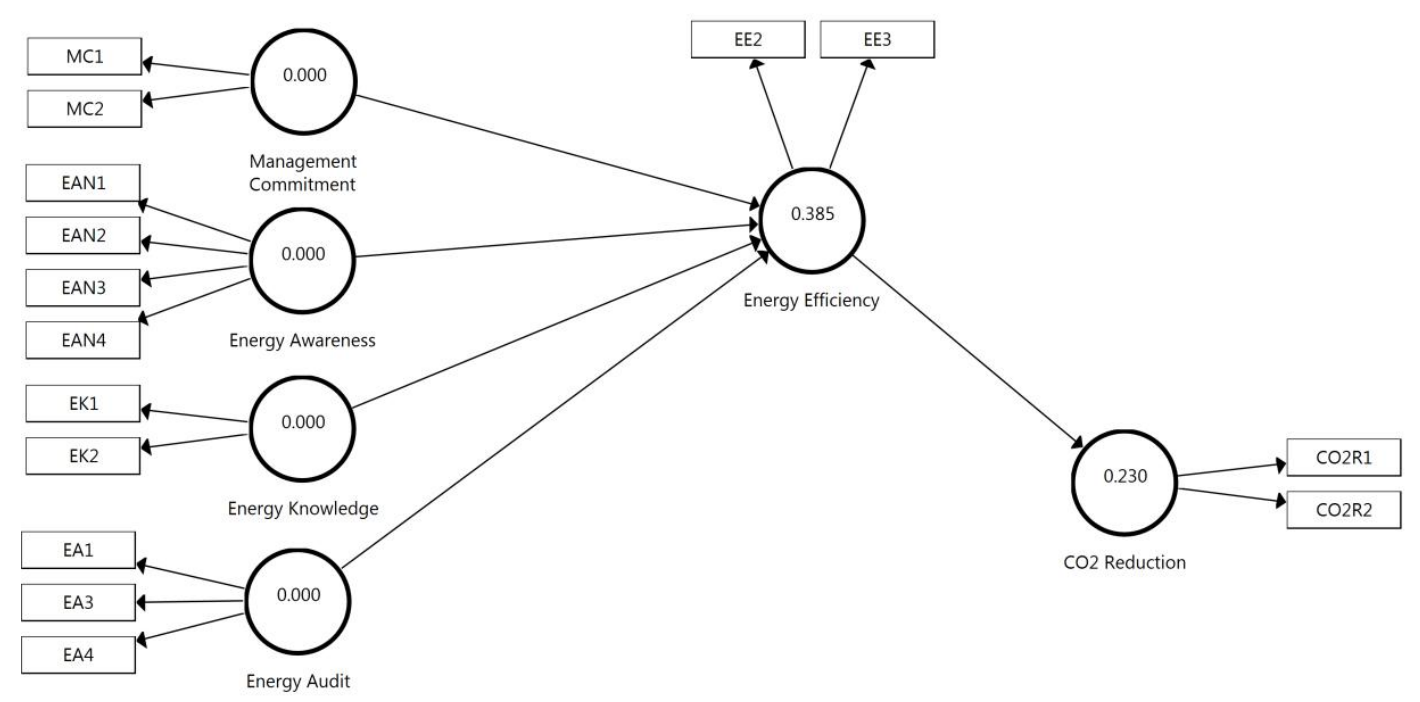

Fig. 4. PLS Blindfolding using SmartPLS

\section{Conclusion}

In developing countries, the researchers and academicians were more vigilant regarding the implementation of energy efficiency and carbon emission reduction. Buyers of public and environmental information are among the forces pushing companies to implement energy conservation to cut carbon emissions. Notwithstanding manufacturing firms' recognition of the need to enhance corporate environmental efficiency, which involves the use of specific organizational tools and skills, carbon emission studies still display negative results for predictors [41]. Such negative findings were addressed in the literature which discusses the strongest predictors of energy efficiency and reduction of carbon emissions. Given this, the present research leads to an awareness of Thailand manufacturing firms' attempts to mitigate environmental concerns.

This research finds that variables such as management commitment, environmental understanding, and environmental literacy are related to energy performance, in line with previous studies of energy management practices [27][42]. Energy audits with a reduction in carbon emissions were found to be significant. The outcomes are constant with those Yao, Zhou, Zhang, and Li [63]; Y.-J. Zhang and Da [68] which means that increases in energy efficiency ultimately contribute to a reduction in total carbon emissions.

Firstly, energy management strategies were successful in increasing energy quality and businesses will continue to invest and improve them for cost-cutting gains and improved operational output. Investing in human resource growth provides signs of determination to produce the desired results and, combined with management encouragement and commitment, the expected success is achievable. Preparation will be made to integrate emerging sustainability ideas as part of information and awareness preparation as an organization matures. Although energy management activities do not affect the elimination of carbon emissions in Thailand, political or economic pressure can inevitably require change or leave a firm behind; thus, it is best to be prepared to take advantage of evolving business conditions as a differentiation strategy to achieve first-mover advantages when the time comes. More notably, management will first grasp the principles and importance of environmental problems and how they should maximize the potential of the organization to explore emerging possibilities that arise from highly managed environments. If the resources of a company were restricted, the minimum advice is to train management to be mindful of these evolving needs for the environment.

\section{References}

[1] Abdmouleh, Z., Alammari, R.A., \& Gastli, A. (2015). Review of policies encouraging renewable energy integration $\&$ best practices. Renewable and Sustainable Energy Reviews, 45, 249-262.

[2] Abunar, M.M. (2016). Factors influencing decision making in internal management: Evidence from private sector organisations in saudi arabia. Brunel University London.

[3] Ahmad, S. (2015). Green human resource management: Policies and practices. Cogent business \& management, 2(1), 1030817. 
[4] Aubin, D.L. (2015). Unmasking the self as a fallible health professional: A grounded theory study on the psychosocial process of mitigating the negative effects of shame due to mistakes.

[5] Baker, M.J. (2003). Data collection-questionnaire design. The marketing review, 3(3), 343-370.

[6] Baumgartner, R.J., \& Rauter, R. (2017). Strategic perspectives of corporate sustainability management to develop a sustainable organization. Journal of Cleaner Production, 140, 81-92.

[7] Ben Jebli, M., Ben Youssef, S., \& Ozturk, I. (2015). The role of renewable energy consumption and trade: Environmental kuznets curve analysis for sub-saharan africa countries. African Development Review, 27(3), 288300.

[8] Bhati, A., Hansen, M., \& Chan, C.M. (2017). Energy conservation through smart homes in a smart city: A lesson for singapore households. Energy Policy, 104, 230-239.

[9] Bilgili, F., Öztürk, İ., Koçak, E., Bulut, Ü., Pamuk, Y., Muğaloğlu, E., \& Bağlitaş, H.H. (2016). The influence of biomass energy consumption on co 2 emissions: A wavelet coherence approach. Environmental Science and Pollution Research, 23(19), 19043-19061.

[10] Board, O.S., \& Council, N.R. (2015). Climate intervention: Reflecting sunlight to cool earth: National Academies Press.

[11] Borén, S., Nurhadi, L., Ny, H., Robèrt, K.-H., Broman, G., \& Trygg, L. (2017). A strategic approach to sustainable transport system development-part 2: The case of a vision for electric vehicle systems in southeast sweden. Journal of Cleaner Production, 140, 62-71.

[12] Brack, W., Escher, B.I., Müller, E., Schmitt-Jansen, M., Schulze, T., Slobodnik, J., \& Hollert, H. (2018). Towards a holistic and solution-oriented monitoring of chemical status of european water bodies: How to support the eu strategy for a non-toxic environment? Environmental Sciences Europe, 30(1), 1-11.

[13] Canton, L.G. (2019). Emergency management: Concepts and strategies for effective programs: John Wiley \& Sons.

[14] Chalermjirapas, T., Theingi, H., \& Aryupong, M. (2019). The study of employee engagement of manufacturing sector in thailand. International Journal of Organizational Innovation, 12(1).

[15] Chin, W.W., Thatcher, J.B., Wright, R.T., \& Steel, D. (2013). Controlling for common method variance in pls analysis: The measured latent marker variable approach New perspectives in partial least squares and related methods (pp. 231-239): Springer.

[16] Chontanawat, J., Wiboonchutikula, P., \& Buddhivanich, A. (2020). An lmdi decomposition analysis of carbon emissions in the thai manufacturing sector. Energy Reports, 6, 705-710.

[17] Cochran, W.G. (2007). Sampling techniques: John Wiley \& Sons.

[18] Connelly, L.M. (2014). Ethical considerations in research studies. Medsurg Nursing, 23(1), 54.

[19] Cooremans, C., \& Schönenberger, A. (2019). Energy management: A key driver of energy-efficiency investment? Journal of Cleaner Production, 230, 264-275.

[20] de Winter, J., \& Dodou, D. (2010). Five-point likert items: T test versus mann-whitney-wilcoxon (addendum added october 2012). Practical Assessment, Research, and Evaluation, 15(1), 11.

[21] Doney, S.C., Busch, D.S., Cooley, S.R., \& Kroeker, K.J. (2020). The impacts of ocean acidification on marine ecosystems and reliant human communities. Annual Review of Environment and Resources, 45.

[22] Fernando, Y., Bee, P.S., Jabbour, C.J.C., \& Thomé, A.M.T. (2018). Understanding the effects of energy management practices on renewable energy supply chains: Implications for energy policy in emerging economies. Energy Policy, 118, 418-428.

[23] Fernando, Y., \& Hor, W.L. (2017). Impacts of energy management practices on energy efficiency and carbon emissions reduction: A survey of malaysian manufacturing firms. Resources, Conservation and Recycling, 126, 6273.

[24] Fleisher, C.S., \& Bensoussan, B.E. (2015). Business and competitive analysis: Effective application of new and classic methods: FT press.

[25] Fornell, C., \& Larcker, D.F. (1981). Structural equation models with unobservable variables and measurement error: Algebra and statistics. Journal of marketing research, 18(3), 382-388.

[26] Gillingham, K., \& Stock, J.H. (2018). The cost of reducing greenhouse gas emissions. Journal of Economic Perspectives, 32(4), 53-72.

[27] Goldman, D., Ayalon, O., Baum, D., \& Weiss, B. (2018). Influence of 'green school certification'on students' environmental literacy and adoption of sustainable practice by schools. Journal of cleaner production, 183, 13001313.

[28] Groves, R.M., Fowler Jr, F.J., Couper, M.P., Lepkowski, J.M., Singer, E., \& Tourangeau, R. (2011). Survey methodology (Vol. 561): John Wiley \& Sons. 
[29] Gupta, L., Jain, R., \& Vaszkun, G. (2015). Survey of important issues in uav communication networks. IEEE Communications Surveys \& Tutorials, 18(2), 1123-1152.

[30] Hair, J.F., Gabriel, M., \& Patel, V. (2014). Amos covariance-based structural equation modeling (cb-sem): Guidelines on its application as a marketing research tool. Brazilian Journal of Marketing, 13(2).

[31] Hair, J.F., Hult, G.T.M., Ringle, C., \& Sarstedt, M. (2016). A primer on partial least squares structural equation modeling (pls-sem): Sage Publications.

[32] Henseler, J., Hubona, G., \& Ray, P.A. (2016). Using pls path modeling in new technology research: Updated guidelines. Industrial management \& data systems, 116(1), 2-20.

[33] Hughes, J.A., \& Sharrock, W.W. (2016). The philosophy of social research: Routledge.

[34] Jovanović, B., \& Filipović, J. (2016). Iso 50001 standard-based energy management maturity model-proposal and validation in industry. Journal of Cleaner Production, 112, 2744-2755.

[35] Kang, S.H., Islam, F., \& Tiwari, A.K. (2019). The dynamic relationships among co2 emissions, renewable and nonrenewable energy sources, and economic growth in india: Evidence from time-varying bayesian var model. Structural Change and Economic Dynamics, 50, 90-101.

[36] Kluczek, A., \& Olszewski, P. (2017). Energy audits in industrial processes. Journal of cleaner production, 142, 3437-3453.

[37] Kock, N., \& Hadaya, P. (2018). Minimum sample size estimation in pls-sem: The inverse square root and gamma-exponential methods. Information Systems Journal, 28(1), 227-261.

[38] Koul, L. (2009). Methodology of educational research: Vikas publishing house PVT Ltd.

[39] Krejcie, R.V., \& Morgan, D.W. (1970). Determining sample size for research activities. Educational and psychological measurement, 30(3), 607-610.

[40] Krolczyk, G., Maruda, R., Krolczyk, J., Wojciechowski, S., Mia, M., Nieslony, P., \& Budzik, G. (2019). Ecological trends in machining as a key factor in sustainable production-a review. Journal of Cleaner Production, 218, 601-615.

[41] Lee, K.-H., \& Min, B. (2015). Green r\&d for eco-innovation and its impact on carbon emissions and firm performance. Journal of Cleaner Production, 108, 534-542.

[42] Liu, S.-Y., Yeh, S.-C., Liang, S.-W., Fang, W.-T., \& Tsai, H.-M. (2015). A national investigation of teachers' environmental literacy as a reference for promoting environmental education in taiwan. The Journal of Environmental Education, 46(2), 114-132.

[43] Manan, Z.A., Nawi, W.N.R.M., Alwi, S.R.W., \& Klemeš, J.J. (2017). Advances in process integration research for co2 emission reduction-a review. Journal of cleaner production, 167, 1-13.

[44] Marin, G., Marzucchi, A., \& Zoboli, R. (2015). Smes and barriers to eco-innovation in the eu: Exploring different firm profiles. Journal of Evolutionary Economics, 25(3), 671-705.

[45] McNeill, J.R., \& Engelke, P. (2016). The great acceleration: An environmental history of the anthropocene since 1945: Harvard University Press.

[46] Moretti, M., Djomo, S.N., Azadi, H., May, K., De Vos, K., Van Passel, S., \& Witters, N. (2017). A systematic review of environmental and economic impacts of smart grids. Renewable and Sustainable Energy Reviews, 68, 888-898.

[47] Mudacumura, G.M., Mebratu, D., \& Haque, M.S. (2017). Sustainable development policy and administration: Routledge.

[48] Naidoo, S.S. (2019). Business intelligence systems input: Effects on organizational decision-making. Capella University.

[49] Nejat, P., Jomehzadeh, F., Taheri, M.M., Gohari, M., \& Majid, M.Z.A. (2015). A global review of energy consumption, co2 emissions and policy in the residential sector (with an overview of the top ten co2 emitting countries). Renewable and sustainable energy reviews, 43, 843-862.

[50] Pandurangan, A.P., Ochoa-Montaño, B., Ascher, D.B., \& Blundell, T.L. (2017). Sdm: A server for predicting effects of mutations on protein stability. Nucleic acids research, 45(W1), W229-W235.

[51] Phaup, M. (2019). Budgeting for mandatory spending: Prologue to reform. Public Budgeting \& Finance, 39(1), 2444.

[52] Quartey, P., Turkson, E., Abor, J.Y., \& Iddrisu, A.M. (2017). Financing the growth of smes in africa: What are the contraints to sme financing within ecowas? Review of development finance, 7(1), 18-28.

[53] Sarstedt, M., Ringle, C.M., \& Hair, J.F. (2014). Pls-sem: Looking back and moving forward: Elsevier.

[54] Sauvé, S., Bernard, S., \& Sloan, P. (2016). Environmental sciences, sustainable development and circular economy: Alternative concepts for trans-disciplinary research. Environmental Development, 17, 48-56. 
[55] Schaltegger, S., Burritt, R., \& Petersen, H. (2017). An introduction to corporate environmental management: Striving for sustainability: Routledge.

[56] Schandl, H., Hatfield-Dodds, S., Wiedmann, T., Geschke, A., Cai, Y., West, J., . . Owen, A. (2016). Decoupling global environmental pressure and economic growth: Scenarios for energy use, materials use and carbon emissions. Journal of cleaner production, 132, 45-56.

[57] Shahbazi, A., \& Nasab, B.R. (2016). Carbon capture and storage (ccs) and its impacts on climate change and global warming. J. Pet. Environ. Biotechnol, 7(9).

[58] Svedäng, H., Hammer, M., Heiskanen, A.-S., Häggblom, M., Ilvessalo-Lax, H., Kvarnström, M., . . Vihervaara, P. (2018). Nature's contributions to people and human well-being in a nordic coastal context.

[59] Tozlu, A., Özahi, E., \& Abuşoğlu, A. (2016). Waste to energy technologies for municipal solid waste management in gaziantep. Renewable and Sustainable Energy Reviews, 54, 809-815.

[60] Vivoda, V. (2016). Energy security in japan: Challenges after fukushima: Routledge.

[61] Wang, S., Ouyang, L., Yuan, Y., Ni, X., Han, X., \& Wang, F.-Y. (2019). Blockchain-enabled smart contracts: Architecture, applications, and future trends. IEEE Transactions on Systems, Man, and Cybernetics: Systems, 49(11), 2266-2277.

[62] Wilkinson, N., \& Klaes, M. (2017). An introduction to behavioral economics: Macmillan International Higher Education.

[63] Yao, X., Zhou, H., Zhang, A., \& Li, A. (2015). Regional energy efficiency, carbon emission performance and technology gaps in china: A meta-frontier non-radial directional distance function analysis. Energy Policy, 84, 142154.

[64] Yatim, P., Mamat, M.-N., Mohamad-Zailani, S.H., \& Ramlee, S. (2016). Energy policy shifts towards sustainable energy future for malaysia. Clean Technologies and Environmental Policy, 18(6), 1685-1695.

[65] Yildiz, Ö., Rommel, J., Debor, S., Holstenkamp, L., Mey, F., Müller, J.R., . . Rognli, J. (2015). Renewable energy cooperatives as gatekeepers or facilitators? Recent developments in germany and a multidisciplinary research agenda. Energy Research \& Social Science, 6, 59-73.

[66] Zhang, F., Hu, X., Langari, R., \& Cao, D. (2019). Energy management strategies of connected hevs and phevs: Recent progress and outlook. Progress in Energy and Combustion Science, 73, 235-256.

[67] Zhang, X., Luo, L., \& Skitmore, M. (2015). Household carbon emission research: An analytical review of measurement, influencing factors and mitigation prospects. Journal of Cleaner Production, 103, 873-883.

[68] Zhang, Y.-J., \& Da, Y.-B. (2015). The decomposition of energy-related carbon emission and its decoupling with economic growth in china. Renewable and Sustainable Energy Reviews, 41, 1255-1266.

[69] Zingales, L. (2015). Presidential address: Does finance benefit society? The Journal of Finance, 70(4), 1327-1363.

[70] Zscheischler, J., Westra, S., Van Den Hurk, B.J., Seneviratne, S.I., Ward, P.J., Pitman, A., . . Wahl, T. (2018). Future climate risk from compound events. Nature Climate Change, 8(6), 469-477. 